\title{
Correlation between secondary thrombosis in epileptic patients and serum levels of folate and vitamin B12
}

\author{
HAO ZHOU, HONG-LI HUANG, NUAN WANG and XIAO-HU PANG \\ Department of Neurology, The First People's Hospital of Xuzhou, Xuzhou, Jiangsu 221000, P.R. China
}

Received January 8, 2016; Accepted August 8, 2016

DOI: $10.3892 /$ br.2016.741

\begin{abstract}
Epilepsy is a chronic brain dysfunction syndrome and nervous system disease whose pathogenesis remains to be determined. The aim of the present study was to analyze the correlation between secondary thrombosis and the serum levels of folate and vitamin B12 in epileptic patients, as well as to determine whether the supplementation of folate and vitamin B12 was associated with a decreased incidence of thrombosis, and provide the basis for novel clinical treatment. A total of 37 patients, diagnosed as epileptic with secondary thrombosis between April 2012 and April 2014, were included in the treatment group. A total of 37 epileptic patients without secondary thrombosis were included in the control group. The serum levels of homocysteine, folate and vitamin $\mathrm{B} 12$ in the two groups and in the epileptic patients with intracranial thrombosis or peripheral thrombosis were compared. According to the Guidance of Epilepsy, the patients in the two groups were administered antiepileptic drugs (AEDs) with the supplementation of folate tablet $(0.4 \mathrm{mg} /$ day $)$ and vitamin B12 tablet $(100 \mu \mathrm{g} /$ day $)$. These indicators and the incidence of thrombosis in the two groups were compared after 1 year. The serum levels of homocysteine in the two groups were higher than normal, and the levels in the treatment group were significantly higher than those in the control group. The serum levels of folate and vitamin B12 in the treatment group were significantly higher than those in the control group and the difference was statistically significant $(\mathrm{P}<0.05)$. The Pearson correlation analysis revealed that the serum levels of folate and vitamin B12 were not associated with the serum level of homocysteine $(\mathrm{P}>0.05)$. The logistic regression analysis revealed that the serum levels of folate and vitamin B12 were independent risk factors for epilepsy with secondary thrombosis [folate: odds ratio $(\mathrm{OR})=0.635$, $\mathrm{P}=0.038$; vitamin $\mathrm{B} 12$ : $\mathrm{OR}=0.418, \mathrm{P}=0.042]$. The differences
\end{abstract}

Correspondence to: Dr Hong-Li Huang, Department of Neurology, The First People's Hospital of Xuzhou, 19 Zhongshanbei Road, Xuzhou, Jiangsu 221000, P.R. China

E-mail: hongli_huang1@163.com

Key words: epilepsy, thrombosis, folate, vitamin B12, homocysteine in the serum levels of homocysteine, folate and vitamin B12 in the epileptic patients with intracranial thrombosis or peripheral thrombosis were not statistically significant $(\mathrm{P}>0.05)$. The serum levels of homocysteine in the two groups, were significantly decreased, while the levels of folate and vitamin B12 were significantly increased. The differences in the serum levels of homocysteine, folate and vitamin B12 in the two groups were not statistically significant $(\mathrm{P}>0.05)$. The differences in the incidence of thrombosis in the two groups were not statistically significant $(\mathrm{P}>0.05)$. In conclusion, the serum levels of folate and vitamin B12 were independent of serum homocysteine, and were the dependent risk factors for primary epilepsy with secondary thrombosis. The supplementation of folate and vitamin B12 may be beneficial for the prevention of epilepsy with secondary thrombosis, making it valuable in application.

\section{Introduction}

Epilepsy is a chronic brain dysfunction syndrome and can occur repeatedly. Characteristic are recurrent seizures due to abnormal neuronal discharge (1). Epilepsy is a common nervous system disease, only second to stroke (2). Currently, the pathogenesis mechanism of epilepsy has not been fully understood. It was believed that genetics, central nervous system diseases, acquired brain injury and nervous system diseases could result in epilepsy (3). In the cases of hemorrhagic or ischemic stroke, $12.8 \%$ of the patients may have secondary epilepsy, especially tonic-clonic seizures (4).

The serum levels of homocysteine in epileptic patients were significantly higher than those in the normal population. Hyper homocysteinemia was a key factor of thrombosis and other cardiovascular diseases. It was reported that the incidence of secondary ischemic stroke in the epileptic patients, who had no primary cardiovascular diseases, was $0.52-1.27 \%$ (5). However, the correlation between secondary thrombosis and the serum level of homocysteine in epileptic patients was less reported, and the correlation between increasing/decreasing serum folate and vitamin B12 and the epilepsy with secondary thrombosis has not been previously described. The aim of this study was to determine whether epilepsy with secondary thrombosis was associated with the serum levels of homocysteine and vitamin B12. Thus, a comparison of the serum levels in simple epilepsy patients without secondary thrombosis through non-intervention experiment was made. 


\section{Materials and methods}

General information. A total of 37 patients, diagnosed as epileptic with secondary thrombosis in the First People's Hospital (Jiangsu, China) between April 2012 and April 2014, were included in the treatment group. A total of 37 epileptic patients without secondary thrombosis were included in the control group. The patients in the two groups were diagnosed as epileptic based on the clinical symptoms, electroencephalogram (EEG) and active EEG. The exclusion criteria were: i) Age $<18$ years; ii) pregnancy; iii) primary cerebral vascular disease, the history of trauma surgery, high agglutination, severe heart, liver and kidney dysfunction, and malignancy; iv) persistent and uncontrollable epileptic seizure; and v) refusal to participate in this study. There were 20 males and 17 females in the treatment group, with a mean age of $45.6 \pm 5.4$ (31-63) years. The mean disease course was $4.6 \pm 1.2$ years ( 3 months-17 years). In these patients, there were 19 cases of tonic-clonic seizures, 11 cases of single partial seizures, 5 cases of complex partial seizures, 2 cases of epileptic state, as well as 16 cases in the temporal lobe, 13 cases in the basal ganglia, 4 cases in the parietotemporal region and 4 cases in the frontal lobe. There were 15 patients receiving antiepileptic drug (AED) monotherapy, 14 patients receiving two AEDs in combination and 8 patients receiving three AEDs in combination. A total of 21 cases of secondary intracranial thrombosis, 12 cases of peripheral thrombosis and 4 cases of intracranial and peripheral thrombosis were confirmed. There were 21 males and 16 females in the control group, with a mean age of $48.4 \pm 6.5$ (22-74) years. The mean disease course was $4.9 \pm 1.3$ years ( 1 month- 15 years). In these patients, there were 20 cases of tonic-clonic seizures, 12 cases of single partial seizures, 4 cases of complex partial seizures and 1 case of epileptic state, as well as 17 cases in the temporal lobe, 12 cases in the basal ganglia, 6 cases in the parietotemporal region and 2 cases in the frontal lobe. There were 18 patients receiving AED monotherapy, 13 patients receiving two AEDs in combination and 6 patients receiving three AEDs in combination. These patients were comparable with respect to gender, age, disease course, epilepsy type, location and AEDs ( $\mathrm{P}>0.05)$.

Approval for the study was obtained from the Local Ethics Committee. Informed consent was obtained from the patients family members.

Methods. Serum levels of homocysteine, folate and vitamin B12 in the two groups, and the serum levels of homocysteine, folate and vitamin B12 in the epileptic patients with secondary intracranial or peripheral thrombosis were analyzed. According to the Guidance of Epilepsy, these patients received AEDs and the supplementation of folate tablet $(0.4 \mathrm{mg} /$ day $)$ and vitamin B12 tablet $(100 \mu \mathrm{g} / \mathrm{day})$. The serum levels of homocysteine, folate and vitamin B12, and the incidence (or recurrence rate) of thrombosis in these patients after 1 year was compared.

Blood $(5 \mathrm{ml})$ was collected from the ulnar vein of fasting patients in the early morning, and $1.8 \mathrm{ml}$ blood was mixed with $0.2 \mathrm{ml}$ sodium citrate $(0.13 \mathrm{nmol} / \mathrm{l})$ for separation. The remaining blood specimens were stored at $-20^{\circ} \mathrm{C}$ after coagulation. The fluorescence detector and the reagent kit were provided by Taiwan's Formosa Biomedical Technology Co. Ltd. (Taipei, Taiwan, R.O.C.). The serum level of homocysteine was determined following the manufacturer's instructions.
Table I. Serum levels of homocysteine, folate and vitamin B12 in the two groups.

\begin{tabular}{lccc}
\hline Group & $\begin{array}{c}\text { Homocysteine } \\
(\mu \mathrm{mol} / \mathrm{l})\end{array}$ & $\begin{array}{c}\text { Folate } \\
(\mathrm{ng} / \mathrm{ml})\end{array}$ & $\begin{array}{c}\text { Vitamin B12 } \\
(\mathrm{pg} / \mathrm{ml})\end{array}$ \\
\hline Treatment & $18.7 \pm 2.3$ & $4.2 \pm 1.5$ & $341.6 \pm 47.2$ \\
Control & $16.3 \pm 2.1$ & $6.7 \pm 1.1$ & $435.3 \pm 33.7$ \\
T-value & 1.786 & 2.635 & 3.531 \\
P-value & 0.041 & 0.033 & 0.028 \\
\hline
\end{tabular}

Table II. Serum levels of homocysteine, folate and vitamin B12 in the epileptic patients with intracranial thrombosis or peripheral thrombosis.

\begin{tabular}{lccc}
\hline Group & $\begin{array}{c}\text { Homocysteine } \\
(\mu \mathrm{mol} / \mathrm{l})\end{array}$ & $\begin{array}{c}\text { Folate } \\
(\mathrm{ng} / \mathrm{ml})\end{array}$ & $\begin{array}{c}\text { Vitamin B12 } \\
(\mathrm{pg} / \mathrm{ml})\end{array}$ \\
\hline $\begin{array}{l}\text { Intracranial } \\
\text { thrombosis }\end{array}$ & $20.3 \pm 3.2$ & $3.8 \pm 1.2$ & $351.3 \pm 25.5$ \\
$\begin{array}{l}\text { Peripheral } \\
\text { thrombosis }\end{array}$ & $18.8 \pm 2.5$ & $4.1 \pm 1.7$ & $348.2 \pm 41.4$ \\
$\begin{array}{l}\text { T-value } \\
\text { P-value }\end{array}$ & 0.523 & 0.638 & 0.926 \\
\hline
\end{tabular}

The 180SE automatic chemiluminescence detector (Bayer, Pittsburgh, PA, USA) and the reagent kit were used to detect the serum levels of folate and vitamin B12, following the manufacturer's instructions. Under fasting conditions, the reference range of homocysteine, folate and vitamin B12 was 5-12 $\mu \mathrm{mol} / 1,3-17 \mathrm{ng} / \mathrm{ml}$, and $173-878 \mathrm{pg} / \mathrm{ml}$, respectively.

Statistical analysis. SPSS 17.0 software (IBM SPSS, Armonk, NY, USA) was used for the analysis of all the data in this study. Quantitative data were presented by mean \pm standard deviation, and the inter-group comparison was performed by a t-test. Qualitative data were presented by number or $\%$, and the intergroup comparison was performed by the Chi-square test. The correlation between the serum levels of folate and vitamin B12 and the serum level of homocysteine was analyzed by the Pearson correlation test. The screening of the risk factors in the epileptic patients with secondary thrombosis was analyzed by logistic regression analysis. $\mathrm{P}<0.05$ was considered to indicate a statistically significant difference.

\section{Results}

Serum levels of homocysteine, folate and vitamin B12 in the two groups. As shown in Table I, the serum levels of homocysteine in the two groups were higher than normal, and the levels in the treatment group were significantly higher than those in the control group and the difference was statistically significant (treatment: $18.7 \pm 2.3 \mu \mathrm{mol} / 1$ vs. control: $16.3 \pm 2.1 \mu \mathrm{mol} / 1$; $\mathrm{P}<0.05)$. Serum levels of folate and vitamin B12 in the treatment group were significantly higher than those in the control group and the difference was statistically significant (folate: 
Table III. The serum levels of homocysteine, folate and vitamin B12 in the two groups after treatment.

\begin{tabular}{lccccc}
\hline Group & No. of patients & Homocysteine $(\mu \mathrm{mol} / \mathrm{l})$ & Folate $(\mathrm{ng} / \mathrm{ml})$ & Vitamin B12 $(\mathrm{pg} / \mathrm{ml})$ & Incidence of thrombosis $(\%)$ \\
\hline Treatment & 37 & $14.2 \pm 1.4$ & $8.2 \pm 1.3$ & $625.4 \pm 45.6$ & $4(10.8)$ \\
Control & 37 & $13.3 \pm 1.5$ & $9.1 \pm 1.5$ & $633.8 \pm 52.4$ & $3(8.1)$ \\
T-value $\left(\chi^{2}\right)$ & & 0.124 & 0.856 & 0.758 & 0.639 \\
P-value & 0.302 & 0.421 & 0.323 & 0.452 \\
\hline
\end{tabular}

treatment: $4.2 \pm 1.5 \mathrm{ng} / \mathrm{ml}$ vs. control:6.7 $\pm 1.1 \mathrm{ng} / \mathrm{ml} ; \mathrm{P}<0.05$ and vitamin B12: treatment: $341.6 \pm 47.2 \mathrm{pg} / \mathrm{ml}$ vs. control: $435.3 \pm 33.7 \mathrm{pg} / \mathrm{ml} ; \mathrm{P}<0.05)$.

According to the Pearson correlation analysis, the serum levels of folate and vitamin B12 were not associated with homocysteine (folate and homocysteine: $\mathrm{r}=0.024, \mathrm{P}=0.923$; vitamin $\mathrm{B} 12$ and homocysteine, $\mathrm{r}=0.123, \mathrm{P}=0.745$ ). Epilepsy with secondary thrombosis was selected as the dependent variable, and gender, age, disease course, epilepsy type, location, AEDs, homocysteine, folate and vitamin B12 were selected as the independent variables. A logistic regression analysis with the stepwise backward method was used to screen the dependent variables, and it was found that serum levels of folate and vitamin B12 were the independent risk factors for the epilepsy with secondary thrombosis [folate: odds ratio $(\mathrm{OR})=0.635$, $\mathrm{P}=0.038$; vitamin $\mathrm{B} 12$ : $\mathrm{OR}=0.418, \mathrm{P}=0.042]$.

Serum levels of homocysteine, folate and vitamin B12 in epileptic patients with intracranial thrombosis or peripheral thrombosis. As shown in Table II, the differences in the serum levels of homocysteine, folate and vitamin B12 in the epileptic patients with intracranial thrombosis or peripheral thrombosis were not statistically significant (homocysteine:intracranial: 20.3 $\pm 3.2 \mu \mathrm{mol} / 1$ vs. peripheral: $18.8 \pm 2.5 \mu \mathrm{mol} / 1$; $\mathrm{P}>0.05$; folate:intracranial: $3.8 \pm 1.2 \mathrm{ng} / \mathrm{ml}$ vs. peripheral $: 4.1 \pm 1.7 \mathrm{ng} / \mathrm{ml}$; $\mathrm{P}>0.05$; vitamin B12:intracranial: $351.3 \pm 25.5 \mathrm{pg} / \mathrm{ml}$ vs. peripheral: $348.2 \pm 41.4 \mathrm{pg} / \mathrm{ml}$; $\mathrm{P}>0.05$ ).

Serum levels of homocysteine, folate and vitamin B12 in the two groups after treatment. As shown in Table III, the levels of homocysteine in the two groups were significantly decreased after treatment, while the levels of folate and vitamin B12 in the two groups were significantly increased after treatment. Differences in the serum levels of homocysteine, folate and vitamin B12 in the two groups were not statistically significant after treatment $(\mathrm{P}>0.05)$. The difference in the incidence (or recurrence rate) of thrombosis in the two groups were statistically significant after treatment $(\mathrm{P}>0.05)$.

\section{Discussion}

Secondary epilepsy after stroke has been clinically confirmed, and may be the main etiology of elderly epileptic patients (6). The pathogenesis of secondary epilepsy after stroke involves the stability of neuronal cells affected by tissue ischemia, hypoxia, edema and metabolic disorders after stroke, the mechanical stimulus from the epileptogenic focus formed in the scar tissue after stroke, and gradual occurrence of neuronal degeneration, gliosis, scarring, atrophy and adhesions displacement (7).
However, with increasing clinical experience, long-time seizure in epileptic patients without primary cerebrovascular diseases may result in thrombosis. Investigators suggested that AEDs may cause thrombosis to some extent. Cerebral thrombosis may lead to ischemic stroke, and peripheral thrombosis to limb arterial-venous embolism (8). Thrombosis involves the mass formed by the accumulation of blood in the inner lining of blood vessels, composed of insoluble fibrin and platelets. Thrombosis is the result of the interactions of multiple factors. Previous findings suggested that the serum level of homocysteine in epileptic patients was higher to a varying degree (9). Homocysteine is the intermediate product of cysteine and methionine metabolism, and may cause vascular endothelial cell permeability dysfunction, leading to the precipitation of cholesterol and lipoproteins on vascular wall, inactivation of vasodilation factors, promotion of the formation of prostaglandins and thromboxane, enhance the activity of clotting factor, and accelerate the accumulation of platelets. As a result, thrombosis was formed. Homocysteine is an independent risk factor of thrombosis. The higher the serum levels of homocysteine in patients, the higher the risk of thrombosis (10).

However, the correlation between homocysteine and thrombosis remains to be determined. This study compared the serum levels of homocysteine, folate and vitamin B12 in the epileptic patients with secondary thrombosis and the simple epileptic patients without secondary thrombosis through a non-intervention experiment. The serum levels of homocysteine in the two groups were higher than normal, the levels of homocysteine were significantly higher in the treatment group than in the control group, and the serum levels of folate and vitamin B12 were significantly lower in the treatment group than in the control group and the differences were statistically significant $(\mathrm{P}<0.05)$. The Pearson correlation analysis revealed that the serum levels of folate and vitamin B12 were not significantly associated with the serum level of homocysteine. The logistic regression analysis revealed that the serum levels of folate and vitamin B12 were the independent risk factors for epilepsy with secondary thrombosis. Although the sample size in this study was small, and the risk factors of thrombosis, such as platelets and fibrinogen, were not involved, we may conclude that the serum levels of folate and vitamin B12 were independent of homocysteine and were the independent risk factors for primary epilepsy with secondary thrombosis.

The mechanism of epilepsy with secondary thrombosis caused by folate and vitamin B12 has not been reported. The reason may be that folate was composed of glutamic acid, methotrexate pyridine, and p-aminobenzoic acid, and was a necessary nutrient in the body and played important roles in the synthesis of DNA, RNA, and proteins. Vitamin B12 and 
folate were the coenzymes of the key enzymes in homocysteine metabolism (11-14). This study used supplementation of folate and vitamin B12, and found that the differences in the incidence of thrombosis in these patients were not statistically significant. Thus, folate and vitamin B12 were associated with the pathogenesis of epilepsy with secondary thrombosis, higher serum levels of folate and vitamin B12 could reduce the incidence of thrombosis. Some studies suggested that long-time antiepileptic treatment may decrease the level of $B$ vitamins in the body, while some AEDs may increase the activity of methionine synthetase and the serum level of homocysteine, thus increasing the risk of epilepsy with secondary thrombosis $(15,16)$. In the present study, all the patients in the treatment and control groups received regular AEDs, and had no increased incidence of thrombosis. This result indicated that AEDs may be irrelevant to the serum levels of folate and vitamin B12 (17,18). Currently, the correlation between the change of the serum levels of folate and vitamin B12 and the pathogenesis, development of epilepsy and secondary thrombosis, and the intrinsic mechanism is in preliminary investigation. Animal model and clinical controlled trials are required for further elucidation of the mechanism.

In summary, the serum levels of folate and vitamin B12 may be independent of homocysteine, and the independent risk factors for primary epilepsy with secondary thrombosis. The supplementation of folate and vitamin B12 may be beneficial to the prevention of epilepsy with secondary thrombosis, and may be valuable in application.

\section{References}

1. Jessberger S and Parent JM: Epilepsy and adult neurogenesis Cold Spring Harb Perspect Biol 7: Nov 9, 2015 (Epub ahead of print).

2. Devinsky O, Spruill T, Thurman D and Friedman D: Recognizing and preventing epilepsy-related mortality: A call for action. Neurology 86: 779-786, 2016.

3. Kosyfaki P, Woerner W and Att W: Prosthodontic treatment in a partially edentulous patient with a complex medical history of epilepsy and deep vein thrombosis: A case report. Quintessence Int 42: 365-373, 2011

4. Grover PJ, Jayaram R and Madder H: Management of cerebral venous thrombosis in a patient with Lane-Hamilton syndrome and coeliac disease, epilepsy and cerebral calcification syndrome. Br J Neurosurg 24: 684-685, 2010.

5. Achilli C, Jadhav SA, Guidetti GF, Ciana A, Abbonante V, Malara A, Fagnoni M, Torti M, Balduini A, Balduini C, et al: Folic acid-conjugated 4-amino-phenylboronate, a boron-containing compound designed for boron neutron capture therapy, is an unexpected agonist for human neutrophils and platelets. Chem Biol Drug Des 83: 532-540, 2014.
6. Cacciapuoti F: Lowering homocysteine levels with folic acid and B-vitamins do not reduce early atherosclerosis, but could interfere with cognitive decline and Alzheimer's disease. J Thromb Thrombolysis 36: 258-262, 2013.

7. Mierzecki A, Kłoda K, Jastrzębska M, Chełstowski K, Honczarenko K, Kozłowska-Wojciechowska $M$ and Naruszewicz M: Is there an effect of folic acid supplementation on the coagulation factors and C-reactive protein concentrations in subjects with atherosclerosis risk factors? Postepy Hig Med Dosw Online 66: 696-701, 2012.

8. Jardine MJ, Kang A, Zoungas S, Navaneethan SD, Ninomiya T, Nigwekar SU, Gallagher MP, Cass A, Strippoli G and Perkovic V: The effect of folic acid based homocysteine lowering on cardiovascular events in people with kidney disease: Systematic review and meta-analysis. BMJ 344: e3533, 2012.

9. Kolling J, Scherer EB, da Cunha AA, da Cunha MJ and Wyse AT: Homocysteine induces oxidative-nitrative stress in heart of rats: Prevention by folic acid. Cardiovasc Toxicol 11: 67-73, 2011

10. Brazzelli V, Grasso V, Fornara L, Moggio E, Gamba G, Villani S and Borroni G: Homocysteine, vitamin B12 and folic acid levels in psoriatic patients and correlation with disease severity. Int $\mathrm{J}$ Immunopathol Pharmacol 23: 911-916, 2010.

11. Salemi G, Gueli MC, D'Amelio M, Saia V, Mangiapane P, Aridon P, Ragonese P and Lupo I: Blood levels of homocysteine, cysteine, glutathione, folic acid, and vitamin B12 in the acute phase of atherothrombotic stroke. Neurol Sci 30: 361-364, 2009.

12. Cakmak SK, Gül U, Kiliç C, Gönül M, Soylu S and Kiliç A: Homocysteine, vitamin B12 and folic acid levels in psoriasis patients. J Eur Acad Dermatol Venereol 23: 300-303, 2009.

13. Zhou K, Zhao R, Geng Z, Jiang L, Cao Y, Xu D, Liu Y, Huang L and Zhou J: Association between B-group vitamins and venous thrombosis: Systematic review and meta-analysis of epidemiological studies. J Thromb Thrombolysis 34: 459-467, 2012.

14. Whyte AF, Jones DL and Dreyer MD: Vitamin B12 deficiency causing hyperhomocysteinaemia and cerebral venous sinus thrombosis. Intern Med J 42: 601-603, 2012.

15. Remacha AF, Souto JC, Piñana JL, Sardà MP, Queraltó JM, Martí-Fabregas J, García-Moll X, Férnandez C, Rodriguez A and Cuesta J: Vitamin B12 deficiency, hyperhomocysteinemia and thrombosis: A case and control study. Int J Hematol 93: 458-464, 2011.

16. Lin HY, Chung CY, Chang CS, Wang ML, Lin JS and Shen MC: Hyperhomocysteinemia, deep vein thrombosis and vitamin B12 deficiency in a metformin-treated diabetic patient. J Formos Med Assoc 106: 774-778, 2007.

17. Spada RS, Stella G, Calabrese S, Bosco P, Anello G, Guéant-Rodriguez RM, Romano A, Benamghar L, Fontaine T and Guéant JL: Association of vitamin B12, folate and homocysteine with functional and pathological characteristics of the elderly in a mountainous village in Sicily. Clin Chem Lab Med 45: 136-142, 2007.

18. Sirachainan N, Tapanapruksakul P, Visudtibhan A, Chuansumrit A, Cheeramakara C, Atamasirikul K, Chotsuppakarn S and Areekul S: Homocysteine, MTHFR C677 T, vitamin B12, and folate levels in Thai children with ischemic stroke: A case-control study. J Pediatr Hematol Oncol 28: 803-808, 2006. 